\title{
Maiakóvski em português
}

Apresentação de BORIS SCHNAIDERMAN

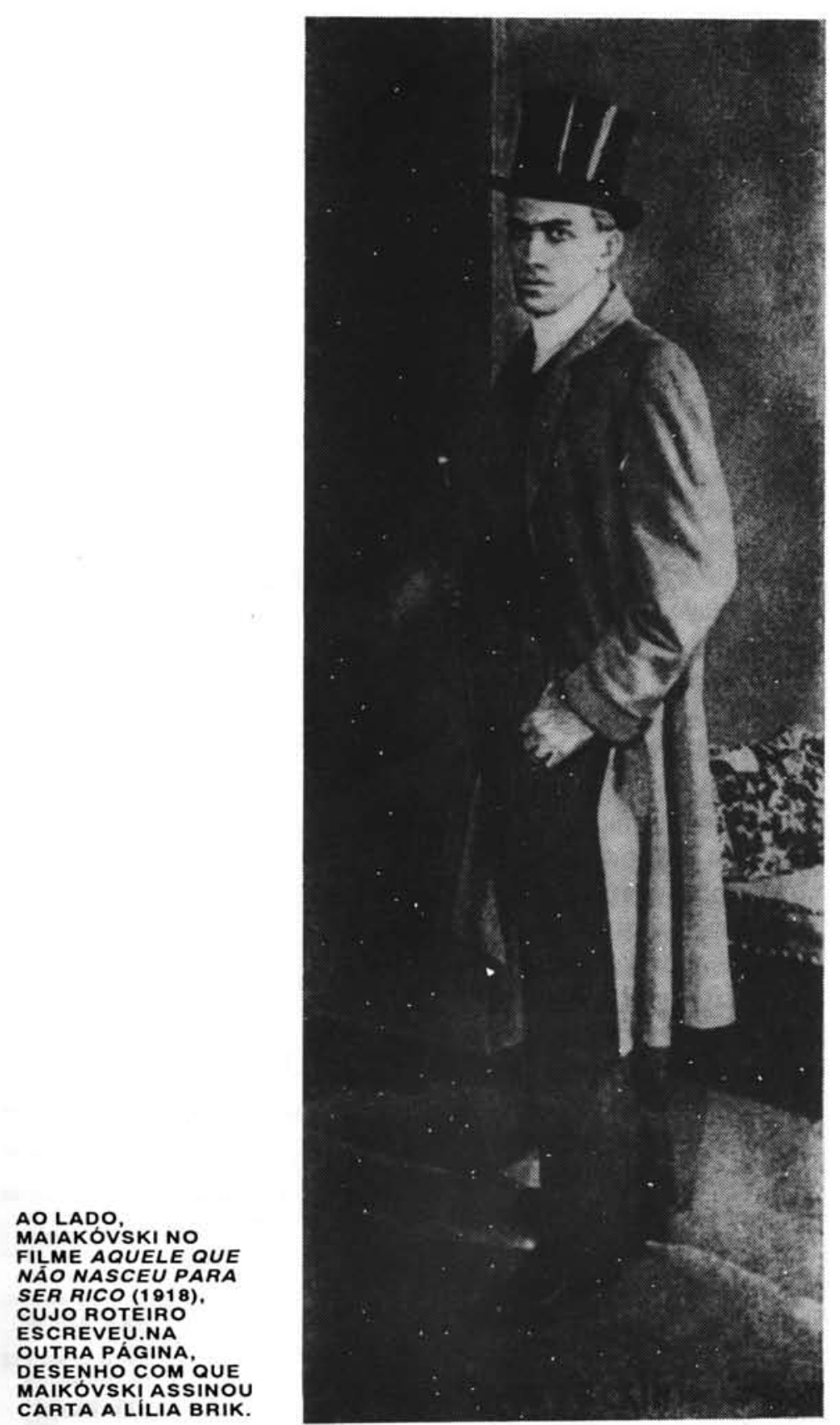

A Revista USP publica a seguir várias traduções de poemas de Maiakóvski, todas com utilização do texto russo. Como se vê, depois do trabalho realizado por Augusto e Haroldo de Campos com a minha colaboração, a partir da década de 1960 , e que resultou na antologia atualmente editada pela Perspectiva, diversos tradutores mais jovens de poesia se dedicaram à mesma tarefa. Éverdade que a obra do poeta é bem vasta e falta ainda percorrer um longo caminho, mas o que se obteve até agora ébem auspicioso e mostra que já se alcançou, no Brasil, um nível de qualidade apreciável, pois as traduções que apresentamos agora testemunham a acurada elaboração mesmo de poemas de circunstância de Maiakóvski.

Nelson Ascher trabalhou ora na base de uma tradução minha em prosa, ora sozinho e com a minha leitura a seguir, mas coubelhe sempre a estruturação poética do texto.

Luiz Sampaio Zacchi realizou as suas traduções e depois submeteu o resultado à minha apreciação. Elas acompanham a sua tradução da peça de Maiakóvski $O s \mathrm{Ba}$ nhos, que deverá sair em apêndice ao amplo estudo de sua mulher, Reni Chaves Cardoso Zacchi, sobre esse texto, a ser publicado em livro pela Edusp. Nessas quadras, o poeta, acuado então pelos burocratas do Partido, investe contra eles, a incompreensão da crítica (veja-se a referência a Ermilov), os inimigos da arte moderna (a "arte de esquerda", como se dizia), o psicologismo no palco (sobretudo o do Teatro de Arte de Moscou), etc.

Trajano Vieira, ex-aluno do curso de Russo da USP, realizou o trabalho sem nenhuma participação minha. 


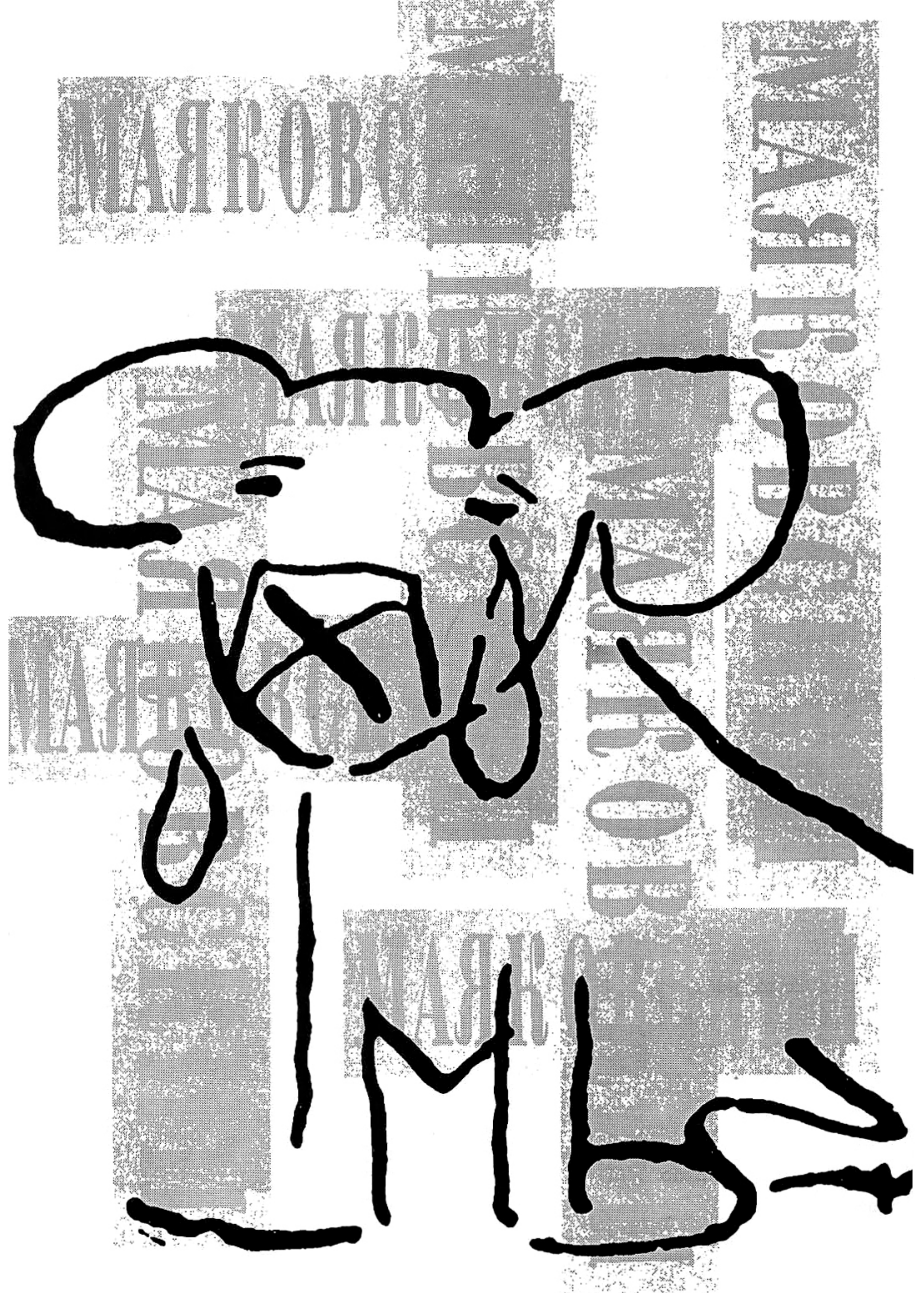




\section{BOA DISPOSIGÁO PARA COM OS CAVAI.OS}

Batiam cascos, cantavam bruscos:

\section{- TRIOUE}

TRAOUE

TROOUE

TRUOUE -

Visco de vento,

lascas de gelo,

na rua deslizante.

O cavalo tombou

de lombo

e, de repente,

malandro após malandro,

abanando a Kuzniétski com as calças,

juntaram-se num bando.

O riso estrídulo estrilava:

- Tropeço de cavalo! -

- Cavalo pelo avesso! -

Uivava todo o mundo.

Apenas eu

não me mesclava no escarcéu.

Cheguei-me e vi no

fundo

olhos eqüinos:

\begin{abstract}
A rua foi a pique,
escorre do seu jeito..

Cheguei-me e vi que

gotona após gotona

escorre pela cara,

esconde-se no pêlo.
\end{abstract}

E não sei que completo

desânimo animal

jorrou de mim abrupto, espalhou-se num farfalho.

"Cavalo, deixa disso.

Cavalo, escuta -

Que pensa, que é pior que todos?

Menino,

nós somos todos algo eqüinos,

cada um, cavalo ao seu modo."

Talvez

- de velho -

nem precisasse de ama-seca, talvez achasse reles meu conselho;

somente,

o cavalo,

de repente,

ergueu-se sobre as patas,

relinchou

e foi em frente.

Zurzia a cauda.

Garoto ruivo.

Chegou feliz co-

locou-se na cocheira.

Pensava ser um outro,

um potro apenas

e viver valia o risco,

trabalhar valia a pena. 


\section{MEU MAIO}

A todos

que saíram às ruas

de corpo pela máquina cansado, a todos

que imploram feriado

às costas que a terra extenua -

Primeiro de maio!

O primeiro dos maios:

saudai-o companheiros enquanto

harmonizamos voz em canto.

Meu mundo em primaveras,

derrete, sol, a neve com teus raios.

Sou operário -

este maio é meu!

Sou camponês -

este é meu maio.

\section{A todos}

curvados à matança carniceira, serpenteando a raiva das trincheiras, a todos

que, dos encouraçados,

apontam de soslaio

canhōes entre escotilhas contra irmãos -

Primeiro de maio!

O primeiro dos maios:

encontrai-o,

trançando agora

as mãos que a guerra desuniu.

Cala-te, guincho de fuzil!

Quieto, rincho de metralhadora!

Sou soldado -

este é meu maio!

Sou marinheiro -

este é meu maio.

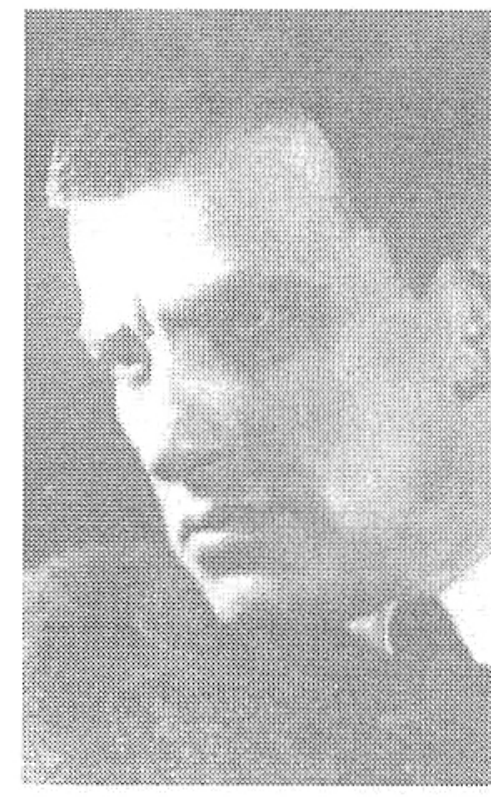

A todas

as casas,

as praças,

as ruas

que o inverno gélido consome,

a todas estas

estepes,

florestas,

searas

roídas pela fome -

Primeiro de maio!

O primeiro dos maios:

celebrai-o,

pessoas,

fertilidade

e primaveras transbordantes!

Verde dos campos, canta!

Uivo das sirenes, ergue-te!

Sou ferro -

este é o meu maio!

Sou terra -

este maio é meu!

(1922) 


\section{DESPEDIDA}

Eis o carro.

Troquei o último franco.

- Que horas parte o trem para Marselha? -

Paris

corre ao meu lado

enquanto arranco,

com toda

a graça incrível

que revela.

Acode,

adeus viscoso,

aos olhos vis,

inunda

o coração

de pieguice!

Viria aqui

viver-morrer,

Paris,

se um tal lugar

- Moscou -

não existisse.

$(1925)$

Traduções de Nelson Ascher

\section{PALAVRAS DE ORDEM PARA O ESPETÁCULO}

\author{
OS BANHOS
}

[No Palco]

Por uma pequena comuna

entregaremos até

os mais maiores maiorais

do Teatro de Ópera e Balé.

Não se prestam
os teatros,
pétreos gigantes,

para alastrar uivos

de câmeras ululantes.

Arrancaremos

os indivíduos

das sacerdotais batas.

Avante, arte,

da massa e para as massas.

Escondam-se, psicovigaristas, nas gaiolas residenciais.

O teatro é arena

para a propaganda dos planos qüinqüenais. 
No cavalo de aço

$$
\text { monte confiante! }
$$

Ofegue

na aldeia,

$$
\text { tratorzão! }
$$

Avante, 25! (1)

$$
25 \text {, avante! }
$$

Operários de aço

$$
\text { um milhão! }
$$

$* * *$

\section{Casas-comunas}

$$
\text { em vez de choupanas! }
$$

Que a massa faça

$$
\text { do Teatro de Arte }
$$

um teatro bacana!

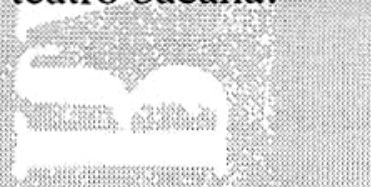

\section{[Na Platéia]}

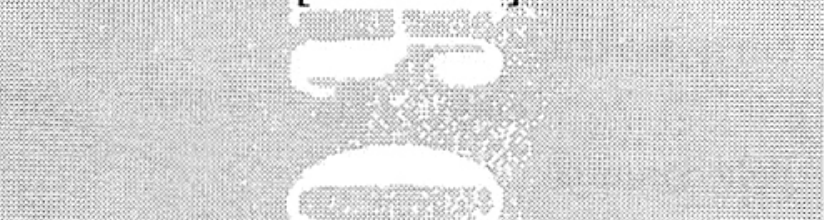

\section{Desmascarem}

$$
\text { já }
$$

os conchavos da direita

$$
\text { e }
$$

da esquerda o blá-blá-blá.

\section{1.* ***}

Abaixo o lixo dos acessórios e dos trapos

[de cor!

Refaça a vida, comunista diretor!
A comuna se constrói com esforço e com

[suores,

A pena do dramaturgo ajuda os constru-

[tores.

De repente

não se evapora

o enxame de burocratas,

Nem banhos

nem sabỗes

bastam, a vós.

E ainda

aos burocratas

$$
\text { auxilia a pena }
$$

de críticos

do tipo de Ermilov...

Entusiasmo,

$$
\text { alastre-se e perdure! }
$$

\section{Usinas}

$$
\text { brilhem altaneiras! }
$$

Hoje

$$
\text { se constrói }
$$

$$
\text { o socialismo }
$$

vivo,

$$
\text { presente, }
$$

verdadeiro. 
Não emporcalhem o teatro com o visgo [psicovigarista!

Teatro, sirva à propaganda comunista!

Alguns dizem:

"Espetáculo maravilhoso, mas ele é incompreensível

à grande massa".

A arrogância senhorial deixem de vez:

a massa

se vira

tão bem como vocês.

Tendo as māos

de clássicos repletas,

mais atentamente

os livrinhos examine,

para que

pelo Teatro de Arte

algum conde seleto (2)

com a mística

a república

năo contamine.

$* * *$
"Comédia

inaceitável

desta maneira”.

Disseram

e

balançaram a cabeça.

Respeitável

Camarada Principal do Controle de Espetáculos e Repertório

passe

não no fim,

mas no começo.

Se aos brancos

der na telha

voltar à vista,

como atacaram

Moscou

$$
\text { no passado, }
$$

em nosso teatro

$$
\text { cada artista }
$$

pela comuna

será um soldado.

Naufraga a luta

no mar da papelada,

que a luta contra os burocratas

seja revitalizada.

Não deixemos que,

$$
\text { por causa de alguns }
$$

cretinos-fôrmas,

piore

a cretinice das formas. 
Aponte os projetores:

na ribalta luz e cor.

Gire:

a ação arrebata

$$
\text { não arrasta o momento. }
$$

O teatro

não é espelho refletor,

mas

lente de aumento.

Apreciem

a arte

que abarrota as caixas,

mas a arte

$$
\text { é o que propaga }
$$

as revolucionárias vozes,

$\mathrm{a}$ arte

é o que brilha

como arma da classe

não se rendam

$$
\text { por nenhum dinheiro }
$$

aos nossos algozes.

\section{PALAVRAS DE ORDEM PARA AS FAIXAS DO FINAL}

Cortem raízes e ramos do capital!

Cabos e correias trabalhando a contento!

Voe ao socialismo no plano qüinqüenal,

Em nossa máquina do tempo!

Avance nação,

$$
\text { não deixe rastro, minha }
$$

a comuna chega aos portões.

Avante, tempo!

Tempo, avante!

[1930]

[1987]

Tradução de Luiz Sampaio Zacchi

1Alusãoa 25 de outubro, data da Revolução Bolchevique pelo calendário então em vigor (hoje 7 de novembro).

2 Alusão possível a Aleksiéi Tolstói. 


\section{HINO AO CIENTISTA}

População de todo o planeta pessoas, pássaros, centopéias, com pêlos hirtos, penas feito setas pula à janela afoita para ver a peça.

E se interessa o sol, até abril acena, interessou ainda ao negro espanador a extraordinária e assombrosa cena: o cientista célebre faz furor.

Olham: nenhuma qualidade humana. Não é um homem, mas um bípede senil. Picadas a cabeça toda inflamam pelo tratado As verrugas no Brasil.

Olhos famintos mordem uma letra. Ah, letra de azar!

Que o ictiossauro em extinção verta a violeta que encontrou no maxilar.

Dobra a espinha, como ao golpe de um [bastão, mas põe reparo num defeito tão tíbio? De Darwin grava os textos no coração: não somos simples filhos dos símios?

A uma exígua brecha o sol se abeira, como pequena chaga purulenta vai se esconder no pó da prateleira, onde uma coleção de tubos senta.

O coração da moça ferve em iodo. Restos petrificados do verão passado. Num alfinete algo como o coto de um infeliz cometa dessecado.
A noite toda vela. O sol desponta rindo sobre a deformidade humana, e nas calçadas já parecem prontos os empenhados ginasianos.

Vão-se os orelhas-roxas. Não lhe importa que a gente cresça mansa e apagada, desde que a todo instante ele possa executar sua raiz quadrada.

\section{AMOR NAVAL}

Corre pelo mar a brincadeira entre torpedeiro e torpedeira.

Como a abelha gruda no meleiro, vai na torpedeira o torpedeiro.

Não termina o plano o companheiro, o benevolente torpedeiro.

Refletor nasóculos, à beira, crava bem atrás da torpedeira.

Urla a voz de cobre sem fronteira: "Atenção: em fuga a torpedeira!"

Esquerda, direita, dianteira, e bate carreira a torpedeira.

Mas um tiro rápido e certeiro racha na costela o torpedeiro.

Choro e grito cruza a água inteira: luto da viúva torpedeira. 
Ao mundo que mal faz a maneira que adota a família torpedeira? (1915)

\section{SÍNDROME DE REUNIÃO}

Susta a noite e o sol já aquece, todo dia a mesma ação: para o glav, para o kom, para o polit, para o prosviet, somem todos na repartição.

Tão logo você chega no edifício, despencam guias em profusão: procure em meia centena os chefes do ofício! -, funcionários somem na reunião.

"Com licença:

Concedem-me uma audiência?

Há um século que espero.”

"O camarada Ivan Vanich? Em reunião, para tratar da Teo e Gukona, em fusão” (1).

Você escala cem escadas.

$\mathrm{O}$ mundo fecha a cara.

De novo:

"Esteja de volta em uma hora.

Reúnem-se:

compram latas de tinta

para a cooperativa da província."

Uma hora depois:

nem secretário, nem secretária nada sob o sol! Todos com 22 anos completos

na reunião da Komsomol (2).

Já anoitece e subo outra vez

o último lance de uma casa de sete.

"Chegou o camarada Ivan Vanich?"

"Em reunião

com o comitê-a-bê-cê-dê-ê-efe."

Furibundo, como uma avalanche irrompo na reunião, vomitando grossos desplantes.

E vejo:

pessoas sentadas pela metade.

Aos diabos!

Onde está a outra metade?

Mutilados!

Assassinados!

Grito feito louco.

O quadro grotesco esmorece o senso.

E ouço

a voz pacata do secretário:

"Em duas reuniões de uma só vez.

Precisamos

ganhar tempo

com vinte reuniões diárias.

Somos forçados a nos dividir.

Até a cintura aqui,

o restante

em outra área." 
Nervoso, não prego o olho.

Amanhece.

Mal amanhece me vem um sonho:

Ah, apenas

mais

uma reunião

para escorraçar todas as reuniões!

(1922)

\section{PONTE DE BROOKLIN}

Coolidge, súbito,

Uiva de júbilo!

Para o que é belo

não poupo estrofe.

Avermelha

com minha ode, como a flâmula feérica,

mesmo sendo

the disunited States

of

America.

Como para a igreja

$$
\text { vai }
$$$$
\text { o crente fanático, }
$$

como no monastério

\section{entra}

circunspecto,

eu

na tarde que acinzenta pela ponte de Brooklin avanço modesto.

Como a cidade

em destroços

cruza o vencedor sobre o canhão - pescoço

de girafa -

com fome de vida, ávido de calor, subo a ponte de Brooklin.

Nada me abafa.

Como artista parvo

na madona de museu

encrava a vista

- coração no estopim -,

eu,

em meio aos cometas,

no arco do céu,

vislumbro

Nova Iorque

da ponte de Brooklin.

Nova Iorque

até o crepúsculo

grave e sem vento

esqueceu

a gravidade

o elevado porte

e apenas algumas

almas dos apartamentos

sobem

à janela

contra o lume forte. 
Aqui

mal titila o tenor

do elevador.

E somente

por esse

baixo tenor,

compreendes -

$$
\text { o trem estrila }
$$

um tímido rumor,

como se

arrumassem a louça no aparador.

Na mina do rio

\section{o mascate}

\section{remove}

açúcar da usina

e os mastros

sob a ponte

já parecem

alfinetes móveis.

Orgulho-me

desta milha de aço.

Minhas visões

acham no alto

sua rota -

luta no fazer,

não estilo,

no espaço,

cálculo exato

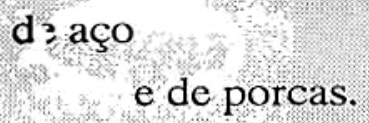

Se

o mundo acabar

em sombra

e o caos

engolir

o nosso globo,

restando apenas

esta ponte empinada

no pó

dos escombros,

então,

como dos ossos

da grossura da agulha,

crescem

nos museus

os dinossauros,

assim,

o geólogo futuro

\section{fará o restauro}

dos dias atuais

a partir desta estrutura.

Dirá:

Esta pata

de aço

unia

mares e pradarias,

daqui

a Europa

arrombava o Ocidente,

lançando

penas de índio

ao vento.

Esta costela

lembra

uma máquina.

Bastaria um braço ágil

para,

com um pé de aço

em Manhattan,

puxar Brooklin

para os lábios?

Os fios

da rede elétrica

não me enganam:

posterior 
à época do vapor.

Aqui as pessoas

já

urlavam no rádio,

aqui as pessoas

já

voavam de aeroplano.

Aqui a vida

foi

para uns - sombra fresca,

para outros -

uivo lento

de carência.

Daqui

os desocupados

jogavam-se

no Hudson

de cabeça.

Sem esforço

minha tela

move-se aqui

por cabos-guelras

até o pé das estrelas.

Vejo -

por este ponto

do som da sílabas passou Maiakóvski,

fez sua centelha.

Olho

como no trem se fixa o esquimó, grudo

como na orelha gruda o carrapato.

Ponte de Brooklin -

E só...

Que belo ato!

(1925)
AO CAMARADA NETTE - AO

NAVIO E AO HOMEM (3)

Quimera do sepulcro?

Na espinha o tremor.

Pelo porto

ardente

como clima que derrete

manobra

entra

$$
\text { o camarada Teodor }
$$

Nette.

É ele.

$$
\text { Reconheço-o. }
$$

Nas lentes-pires dos salva-vidas.

Como vai, Nette!

Que bom revê-lo vivo

na vida-fumo dos tubos

cordas

vigas.

Chega mais perto!

É raso o plano?

De Batum,

$$
\text { creio, o motor fica asmático... }
$$

Lembra, Nette?

Quando era humano

tomávamos chá

no carro diplomático.

Não tinha pressa.

\section{Roncavam}

em volta.

Olhar

de soslaio

no timbre do lacre

falava a noite toda

sobre Romka

Jakobson

e com suor bufo

aprendia minha arte. 
Dormia de manhã.

Mas um dedo

$$
\text { engatilha... }
$$

Avante,

quem for insano!

Podia imaginar

um encontro

$$
\text { com você }
$$

com uma escotilha

ao cabo de um ano?

A lua atrás da popa.

Pousa,

$$
\text { - Esplendor! }
$$

na superfície

rasga um trilho.

Como se pelo eterno

ficasse

a luta do corredor

no rastro do bravo:

sangue e brilho.

No comunismo dos livros

"Num livro

$$
\text { pouco se confia. }
$$

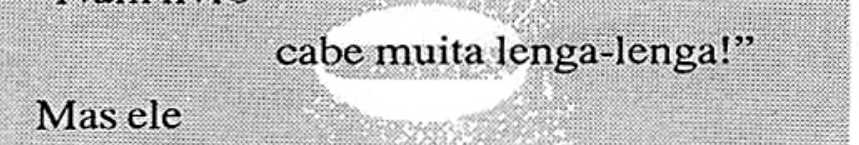

de repente

a vertigem desafia.

Cerne e carne

$$
\text { comunista }
$$

$$
\text { desvenda. }
$$

Em nosso pacto

$$
\text { nã̃o há }
$$

Vamos para a cruz

$$
\text { parcimônia. }
$$

abrimos fogo

por um motivo:

num mundo

$$
\text { sem Rússia, }
$$

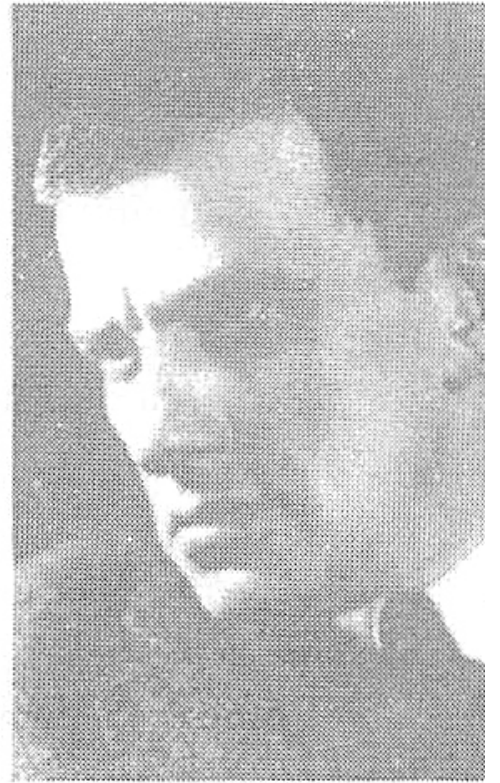

sem Letônia,

vigore

a vida

num só convívio.

Águas nas veias? Não:

sangue.

\section{Cruzamos}

$$
\text { o latido da pistola }
$$

para retornar

$$
\text { adiante }
$$

em navios

$$
\text { poemas }
$$

$$
\text { obras que dobram }
$$

eras.

Que a sobrevida

$$
\text { galope no meu tempo. }
$$

Mas no fim

$$
\text { - não tenho outra meta - }
$$

encontre

$$
\text { no último momento }
$$

a morte

$$
\begin{aligned}
& \text { que encontrou } \\
& \text { o camarada Nette. }
\end{aligned}
$$




\section{ESTOU FEI IZ}

Cidadãos,

um júbilo

gigante me agita:

Ride,

rostos de simpatia!

Devo

$$
\begin{aligned}
& \text { dividir } \\
& \text { o que suscita }
\end{aligned}
$$

mesmo

Hoje

$$
\text { através da poesia. }
$$

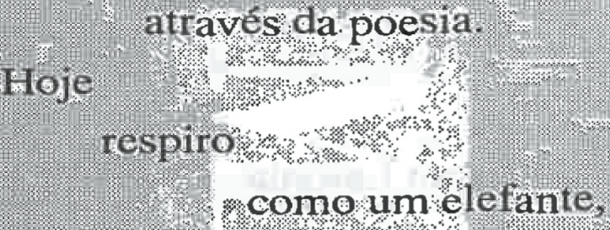

meu pé

$$
\text { mal esbarra }
$$

$$
\text { (2) embaixo }
$$

$$
\begin{aligned}
& \text { passou } \\
& \begin{array}{c}
\text { sem uma so } \\
\text { tosse } \\
\text { ou escarro. }
\end{array}
\end{aligned}
$$

A dose de gozo

$$
\text { e }
$$$$
\text { generosa. }
$$

Dias de outone -

\% odor de banheiro mas para mim

$$
\begin{aligned}
& \text { florescem } \\
& \text { - me perdoem - } \\
& \text { montrosas }
\end{aligned}
$$

e a elas.

notem,

$$
\text { eu me abeiro. }
$$

Rimas,

$$
\text { pontos-de-vista, }
$$

se embelezam

singulares.

Logo arregalam

os olhos

do redator.

Para a labuta

com reservas

retesas

pareço um cavalo

ou talvez

um trator.

As contas

e o estômago,

um estouro:

enrijeço,

tudo entra

nos eixos.

Cem por cento

de economia

no bolso -

ganhei peso

com absoluto êxito.

Como se

depositassem

na língua

fatia

após

fatia

de uma torta oca -

tal o sabor

\section{feérico}

que se aninha

nos cômodos

aromatizados

da boca

A cabeça

\section{por fora}

um brilho vivo 


\section{agora}

brilha

por dentro.

Num dia

uma página

virou aperitivo

e às narinas de Tolstói

um lenço

tem pouca serventia.

Cercaram-me

fêmeas

de roupa furta-cor

com idêntica

\section{curiosidade:}

nome

sobrenome;

tornei-me

um pulcro

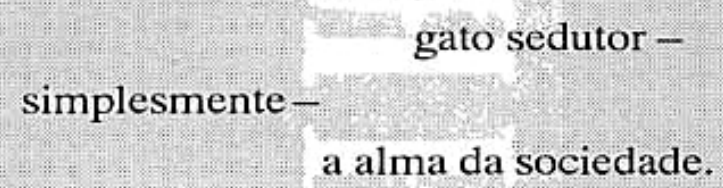

Fiquei rosa,

com o rosto mais gordo,

esqueci

o que é gripe

$$
\text { e cama. }
$$

\section{Querem}

a receita?

\section{Engodo?}

Revelar

ou nâo?

\section{Dúvida humana!}

Fulos,

já fulminem

talvez

cansados

de esperar.

Fui mau?

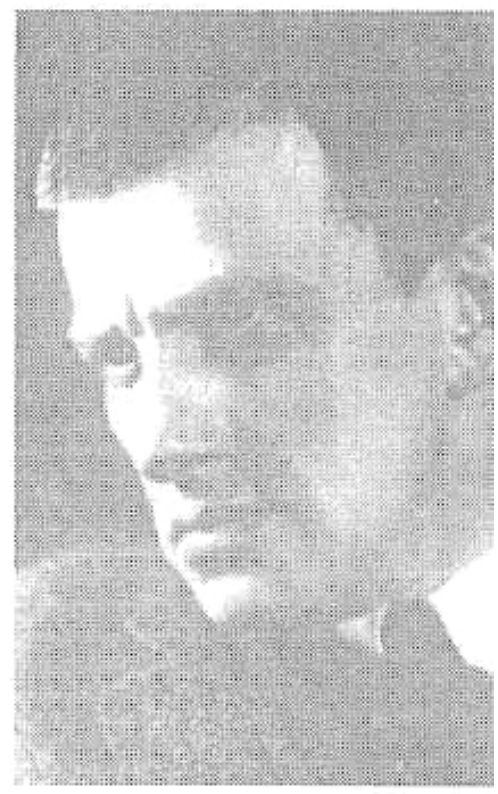

Chegou a vez:

Hoje

eu

parei

de fumar.

\section{Traduçōes de Trajano Vieira}

1 Maiakóvski utiliza jocosamente duas siglas: Teo, seção teatral da Direção para educação política, e Gukon, órgẩo responsável pela criaçāo de cavalos de raça.

2 Komsomol: "Uniāo da Juventude Comunista".

3 Teodor Nette (1896-1926), correio-diplomático, foi assassinado em 5 de fevereiro de 1926, na Letônia, quandose dirigia para Berlim. Foi amigode Maiakóvski e do lingüista Roman Jakobson, mencionado no poema com o apelido Romka. 